\title{
The effect of ice supersaturation and thin cirrus on lapse rates in the upper troposphere
}

\author{
Klaus Gierens ${ }^{1}$, Lena Wilhelm ${ }^{1}$, Sina Hofer ${ }^{1}$, and Susanne Rohs ${ }^{2}$ \\ ${ }^{1}$ Deutsches Zentrum für Luft- und Raumfahrt, Institut für Physik der Atmosphäre, Oberpfaffenhofen, Germany \\ ${ }^{2}$ Forschungszentrum Jülich, IEK-8, Jülich, Germany
}

Correspondence: Klaus Gierens (klaus.gierens@dlr.de)

\begin{abstract}
In this paper, the effects of ice-supersaturated regions and thin, subvisual cirrus clouds on lapse rates are examined. For that, probability distribution and density functions of ten years of measurement data from the MOZAIC/IAGOS project and ERA-5 reanalysis data were produced, and an analysis of an example case of an ice supersaturated region with a large vertical extent is performed. For the study of the probability distribution and density functions, a distinction is made between icesubsaturated, ice-supersaturated air masses and so-called Big Hits, which are situations of particularly high ice-supersaturation that allow the formation of optically thick and strongly warming contrails. The distribution functions show much higher lapse rates, which correspond to almost neutral stratification, for ice-supersaturated regions and Big Hits than for subsaturated air masses. The highest lapse rates are found for Big Hit situations, because of the strong interaction between radiation and high ice-supersaturation.
\end{abstract}

For the examination of an example case, ERA-5 data and forecasts from ICON-EU (DWD) are compared. ERA-5 data, in particular, shows a large ice-supersaturated region below the tropopause, that was pushed up by uplifting air, while the data of ICON-EU indicates areas of saturation. The lapse rate in this ice-supersaturated region (ISSR), which is large, is associated with clouds and high relative humidity. Supersaturation and cloud formation result from uplifting of air layers. The temperature gradient within an uplifting layer steepens, both for dry and moist air, but for moist air there is an additional mechanism: it is the emission and absorption of radiation within the moist air: The upper part of this region emits longwave infrared radiation to space, while the bottom absorbs infrared radiation from lower and warmer layers, which consequently increases the lapse rate. This effect becomes even stronger, if ice crystals are involved (clouds).

\section{Introduction}

Although the existence of ice-supersaturation in the atmosphere is known for more than 100 years (Wegener, 1914; Gierens et al., 2012), the investigation of physical and dynamical characteristics of ice-supersaturated regions (ISSRs) only commenced about 25 years ago, mainly because the then-new MOZAIC project (Measurement of OZone and water vapor by Airbus Inservice airCraft, Marenco et al., 1998) started delivering large amounts of humidity data in the upper troposphere where ISSRs are quite frequent. The airborne data have been used to demonstrate that the degree of supersaturation within ISSRs is exponentially distributed (Gierens et al., 1999) and and how long aircraft fly on average through ISSRs during their cruise 
(Gierens and Spichtinger, 2000). A typical path length is $150 \mathrm{~km}$, but the distribution is heavily skewed to larger values. The MOZAIC data showed that air within midlatitude ISSRs is generally a bit colder and a bit moister than air in the subsaturated neighbourhood. The additional use of satellite data corroborated these results, extended them to ISSRs in the tropics and even over Antarctica (Spichtinger et al., 2003b), and demonstrated a close relation of ice-supersaturation to sub-visible cirrus (Gierens et al., 2000). Using high-resolution radiosonde data for which correction algorithms were applied to the raw humidity data made it possible to derive a thickness distribution for ISSRs (Spichtinger et al., 2003a) with a typical value of a few hundred metres, again with a skewed distribution. Later studies using airborne, satellite, or corrected radiosonde data refined but essentially confirmed these early results (for a review, see Gierens et al., 2012, and references therein).

The European Centre for Medium Range Weather Forecast (ECMWF) was the first weather centre to introduce ice-supersaturation in their forecast model in 2006 (model version C31R1 of the integrated forecast system, IFS, Tompkins et al., 2007) and consequently, ice supersaturation was later also represented in its reanalysis products ERA-Interim (Dee et al., 2011) and the most recent one ERA-5 (Hersbach et al., 2018a, b, 2020). These data made it possible to investigate the distribution of vertical velocity, divergence and relative vorticity inside and outside of ISSRs (Gierens and Brinkop, 2012). Characteristic differences were found in a study covering Europe and the Tropics and four months of data (June, September and December 2011 and March 2021): Ice supersaturation occurs predominantly in uplifting divergent airmasses and in anticyclonic circulation. ${ }^{1}$

In the present paper we show that also another dynamical characteristic of airmasses, the vertical temperature gradient or lapse rate, displays substantially differing distributions in ice-supersaturated and subsaturated air. We determine the lapse rate from the reanalysis' pressure and temperature values. It turns out that the lapse rate even is the quantity with the least overlapping probability distributions: ISSRs are concentrated at near-neutral conditions (high lapse rate); low lapse rates are very rare for ISSRs but not for subsaturated air.

The paper proceeds with the presentation of the data and methods and then shows two types of results, statistics from 10 years of data and as an example a case with a vertically quite extended ISSR in the upper troposphere. For this case, we use data from two weather models and thus provide en passant a comparison of these two. In the discussion section, we try to give explanations for the surprising coupling between thermodynamics (ISSR) and dynamics (stability). Finally, we summarize the results.

\section{Data and methods}

\subsection{Data from commercial aircraft}

For the first part of the study, a combination of MOZAIC In-service Aircraft for a Global Observing System (IAGOS) and ERA-5 reanalysis data was used. The MOZAIC campaign (Marenco et al., 1998), which in 2011 was transferred into IAGOS (Petzold et al., 2015), is a European Research Infrastructure that offers global in-situ data for meteorological quantities and atmospheric chemical composition. They are produced from fully-automated equipment installed on commercial passenger

\footnotetext{
${ }^{1}$ We may occasionally use the short expression "supersaturated airmass" instead of "airmass including supersaturated water vapour", although this might be misleading. It is only the water vapour which is supersaturated. The air is not.
} 
aircraft. Over 62,000 flights can be accessed at the IAGOS portal (IAGOS Data Portal, 2019). For this study, only flights from MOZAIC (IAGOS CORE) of the years 2000-2009 were selected, amounting to 16,588 flights. From those flights, air temperature $T$ and relative humidity $R H$, as well as the flight position were used for the analysis. Data points were restricted to pressure altitudes at cruise level between $310 \mathrm{hPa}$ and $190 \mathrm{hPa}(9-12 \mathrm{~km})$ and to the research area extending from $30^{\circ} \mathrm{N}$ to $70^{\circ} \mathrm{N}$ latitude (zone with most air traffic) and $125^{\circ} \mathrm{W}$ to $145^{\circ} \mathrm{E}$ longitude. This made sure that most of MOZAIC's flights were covered, while not including too many different climate zones. Only calibrated, reliable data, were considered. Measurements are available every 4 seconds. Temperature data have a precision of $\pm 0.2 \mathrm{~K}$ and an accuracy of $\pm 0.5 \mathrm{~K}$. Relative humidity is given with a precision of $1 \%$ and an accuracy of 5\% (Neis et al., 2015). Measurements with $R H>100 \%$ (RH with respect to liquid water) have been rejected, as this would indicate flying through liquid water clouds, which do not exist at temperatures where contrail formation is possible. The humidity sensor's response slows down with decreasing temperature, from $1 \mathrm{~s}$ at $300 \mathrm{~K}$ to $120 \mathrm{~s}$ at $215 \mathrm{~K}$ (Neis et al., 2015). This implies strong inertia at the cruise level of aircraft. Fortunately, this is not a problem for the present study, since we randomly selected only one percent of the data points, such that on a temporal scale two consecutive data points analyzed were on average $400 \mathrm{~s}$ apart, much more than the mentioned $120 \mathrm{~s}$ inertia time scale. The selection is done using a (0-1)-uniform random number generator that selects data points only if the variate is smaller than 0.01 . This ensured the independence of individual data points and excluded autocorrelation in the dataset. For each selected data point the corresponding weather data from the ERA-5 reanalysis is then collected.

\subsection{Reanalysis data}

The ERA-5 Reanalysis (Hersbach et al., 2018a, b, 2020), as the fifth generation ECMWF reanalysis for the global climate and weather, provides global and consistent analyses and forecast fields from 1950 until present, including a large number of atmospheric, land-surface, and ocean-wave variables, that are produced using 4D-Var data assimilation. ERA-5 forecasts are produced twice daily (00, 12 UTC) using ECMWF's Integrated Forecasting System (IFS). For the statistics of the lapse rate hourly ERA-5 reanalysis data were retrieved from the Copernicus Data Service (Copernicus Climate Change Service (C3S), 2017) for the same years from 2000 to 2009 . Specifically, temperature data on pressure levels 200, 225, 250, and $300 \mathrm{hPa}$, are used in $1 \mathrm{deg} \times 1 \mathrm{deg}$ spatial resolution for calculation of the lapse rate surrounding each of MOZAIC's flight points. Temperature data from ERA-5 agree well with MOZAIC in-situ data and a recent comparison with radiosonde data (Bland et al., 2021) confirms the good quality of the reanalysis' temperature in the upper troposphere and lower stratosphere.

For the case study, ERA-5 fraction of cloud cover, relative humidity, temperature, and wind components $u, v$, and $w$ from 21-03-2021 at 18 UTC were used. The data are given at pressure levels between $1000 \mathrm{hPa}$ and $150 \mathrm{hPa}$. The spacing of the individual levels from $1000 \mathrm{hPa}$ to $750 \mathrm{hPa}$ is $25 \mathrm{hPa}$, from $750 \mathrm{hPa}$ to $250 \mathrm{hPa}$ it is $50 \mathrm{hPa}$ and from $250 \mathrm{hPa}$ to $150 \mathrm{hPa}$ it is $25 \mathrm{hPa}$ again. The area extends horizontally from $5^{\circ} \mathrm{W}$ to $21^{\circ} \mathrm{E}$ (geographic longitude) and from $48^{\circ} \mathrm{N}$ to $56^{\circ} \mathrm{N}$ (geographic latitude). But the region of our interest is particularly from $5^{\circ} \mathrm{W}$ to $21^{\circ} \mathrm{E}$ at $52^{\circ} \mathrm{N}$. 


\subsection{Forecast data}

For the analysis of an example case (see section 3.2) ERA-5 and ICON-EU data were applied. The ICON model (ICOsahedral Nonhydrostatic model, Zängl et al., 2015), which was produced by the German Weather Service (DWD) and the Max-Planck Institute for Meteorology in Hamburg (MPI-M), is a global and regional numerical weather prediction model for short- and medium-range weather forecast. In the horizontal, the spacing of the grid, formed by projecting an icosahedron onto a sphere, is $13 \mathrm{~km}$. In the vertical, the grid consists of 90 layers. The uppermost level is located at $75 \mathrm{~km}$. Near the ground, the vertical layers follow the terrain. With increasing altitude, the signal of the terrain weakens, so that the layer height approaches a constant value. Forecast data is produced daily at 00, 06, 12, and 18 UTC. In addition, simulations with much more refined domains, so-called nests, are possible by bisecting the triangles of the original model. The ICON-EU, with a refined domain for Europe, is very closely linked to the global ICON forecast by two-way nesting. It has a horizontal grid spacing of $6.5 \mathrm{~km}$. The vertical layers go up to level 60 and reach a maximum height of $22.5 \mathrm{~km}$.

The data used for this analysis are obtained from the Pamore service of DWD (https://www.dwd.de/DE/leistungen/pamore/pamore.html ?nn=342666, accessed 18-01-2022). This server provides archived forecast data. Here we use the $6 \mathrm{hr}$ forecast of ICONEU data from a forecast run that started 12 UTC on 21-03-2021. The data are retrieved on a regular $0.0625^{\circ} .0625^{\circ}$ longitude/latitude grid. We retrieved temperature, relative humidity, cloud coverage, and pressure on model levels 15-60 (about $150 \mathrm{hPa}$ to ground).

\subsection{Calculation of lapse rates}

An important quantity to characterise the atmospheric stratification is the static stability which is $\gamma=-\mathrm{d} T / \mathrm{d} z$, i.e. the vertical temperature gradient (times minus one). Alternative expressions for the stability are the corresponding gradient of potential temperature and the Brunt-Väisälä frequency. Here we consider the lapse rate, but the results should be expressable in terms of the alternatives as well. For orientation, we note that dry air in neutral stratification (where a dry airparcel lifted adiabatically does not experience any restoring force) has a dry-adiabatic lapse rate of $9.8 \mathrm{~K} \mathrm{~km}^{-1}$. The condensation (resublimation) of water vapour into ice reduces this value, but only slightly in the uppermost troposphere since the mass concentration of water vapour is very small at these levels. A mean lapse rate for the troposphere is about $6.5 \mathrm{~K} \mathrm{~km}^{-1}$. Further, we note that negative lapse rates are characteristic for the stratosphere and for temperature inversions in the troposphere.

From ten years of MOZAIC and ERA-5 data, a dataset was produced that was initially used to analyze the influence of natural weather variability on the instantaneous radiative effect of persistent contrails and in particular very strongly warming ones, termed Big Hits by Wilhelm et al. (2021). The dataset is now base for a statistical analysis regarding the effect of ISSRs and thin cirrus on the lapse rate. For this study, we use 403502 data records. Note that we take contrail persistence here as a proxy for ice supersaturation although the latter requires that also contrail formation is possible, which means essentially that the temperature must be lower than a threshold that is typically around $-40^{\circ} \mathrm{C}$. We found that the distributions presented below are hardly affected by this additional condition. For a contrail to become strongly warming, that is a Big Hit, ice supersaturation must be high to allow large optical thicknesses and thus a large radiative effect. 
For every flight point, where MOZAIC diagnosed ice subsaturation (358141 cases), ice supersaturation (persistent contrails, 45361), and Big Hits (3961 cases), the lapse rate was calculated from ERA-5 temperature values on the neighbouring pressure levels and from these pressure values. It was derived from the barometric height formula, which relates a relative decrease of atmospheric pressure $p$ to an altitude increase:

$\frac{\mathrm{d} p}{p}=-\frac{g}{R_{d}} \frac{\mathrm{d} h}{T(h)}$.

Here $g$ is the gravitational acceleration (the slight height dependence will be neglected), $R_{d}$ is the special gas constant for dry air, $h$ is the altitude, and $T(h)$ is the temperature at altitude $h$. This equation can be integrated once $T(h)$ is given.

Dealing with model data or discrete profile data there is only information on $T$ at certain levels, here pressure levels, say $T_{0}$ at $p_{0}$ (lower level) and $T_{1}$ at $p_{1}$ (higher level). Without further information, it is justified to assume a constant temperature gradient (or lapse rate) between these two levels. The height difference $\Delta h$ and thus the lapse rate $\left(T_{0}-T_{1}\right) / \Delta h:=\gamma$ can be calculated with this assumption. The integral of the barometric height formula is then:

$\ln \left(\frac{p_{0}}{p_{1}}\right)=\frac{g}{R_{d}} \int_{h_{0}}^{h_{1}} \frac{\mathrm{d} h}{T_{0}+\gamma\left(h-h_{0}\right)}$.

Substituting $\vartheta$ for $T_{0}+\gamma\left(h-h_{0}\right)$ leads to

$\ln \left(\frac{p_{0}}{p_{1}}\right)=\frac{g}{\gamma R_{d}} \int_{T_{0}}^{T_{1}} \frac{\mathrm{d} \vartheta}{\vartheta}=\frac{g}{\gamma R_{d}} \ln \left(\frac{T_{0}}{T_{1}}\right)$.

Solving for $\gamma$ gives the desired result

$135 \gamma=\frac{g}{R_{d}} \frac{\ln \left(T_{0} / T_{1}\right)}{\ln \left(p_{0} / p_{1}\right)}$.

For the statistical analysis of the lapse rate, cumulative distribution functions (cdfs) and probability density functions (pdfs) were produced for conditions of ice subsaturation, ice supersaturation, and Big Hits. For probability densities, the kernel density estimator was computed using the Epanechnikov kernel (Silverman, 1998). Five hundred bins were set for each of the pdfs of $2000-2009$ with maximum and minimum following the lapse rate values. The optimal binsizes were calculated by the program. 

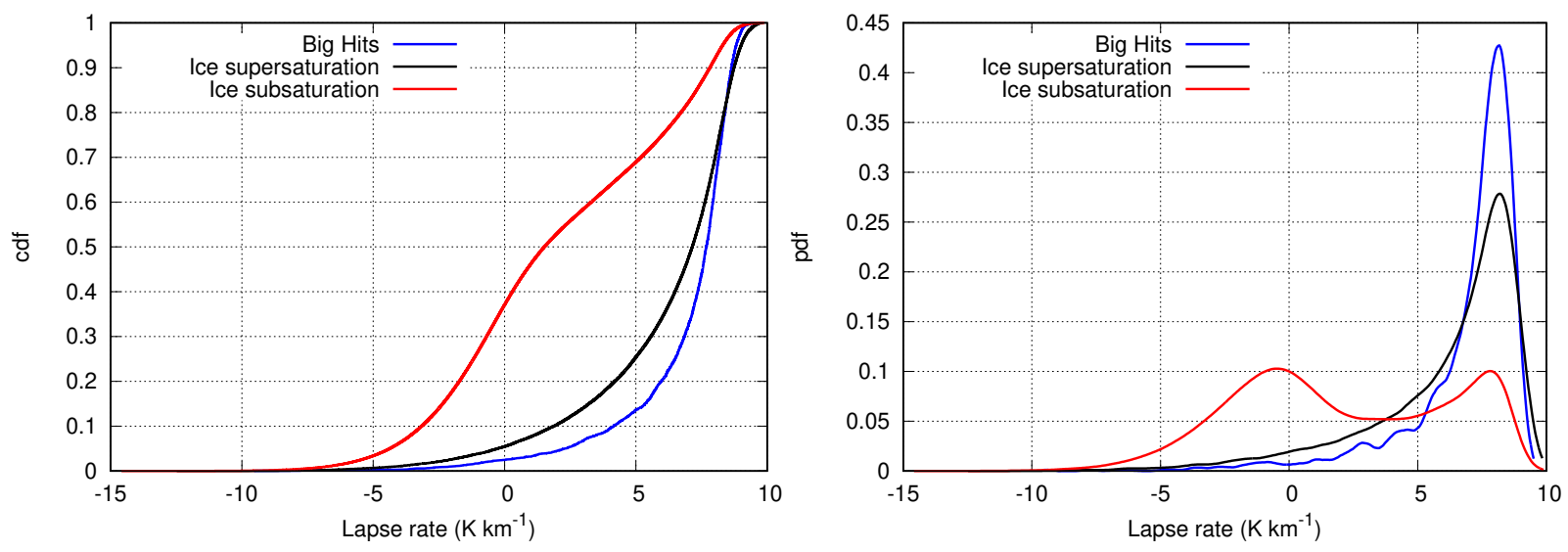

Figure 1. Left panel: Cumulative distribution function of lapse rates, $-d T / d z$, for ice-subsaturated (red) and ice-supersaturated air masses. Right panel: Probability densities for the same lapse rate distributions.

\section{Results}

\subsection{Statistics over 10 years of data}

Figure 1 shows conditional statistical distributions of $\gamma$ for locations and times with subsaturation (red curves), for ISSRs (black; strictly speaking for regions that allow formation of persistent contrails, see above), and for ISSRs that even allowed the formation Big Hits (blue). The left panel shows the three cumulative distribution functions, the right one the corresponding (and equivalent) probability density functions. It is immediately evident that the red curves differ considerably from the other two. ISSRs and Big Hits are predominantly characterized by large lapse rates, close to near neutral stratification. Values below the mentioned mean value of $6.5 \mathrm{~K} \mathrm{~km}^{-1}$ occur in less than about 30\% (ISSRs) and less than about $15 \%$ (Big Hits) of the cases. In contrast, about $75 \%$ of the non-ISSR cases have lapse rates below this mean value. The very rare cases with negative lapse rates for ISSRs and Big Hits are those where the tropopause is below the higher of the two adjacent pressure levels. Then, tropopause and ISSR are very close to each other such that the ISSR is situated just below the tropopause or it even reaches the lowermost stratosphere (see e.g. Petzold et al., 2020). Obviously, the transition from general ISSRs (persistent contrails) to the smaller class of Big Hits that require higher degrees of supersaturation leads to a narrowing of the lapse-rate distribution to the highest values, whereby the peak stays almost the at the same value. That is, the mechanism that steepens the temperature profiles gets stronger with increasing supersaturation. This will be discussed below.

\subsection{An example case}

In the following, an example case of a tall ISSR will be discussed in more detail, that occurred on March 21, 2021 at 18 UTC for several hours over Belgium and the Netherlands. For a geographic assignment and an overview of the synoptic conditions, 


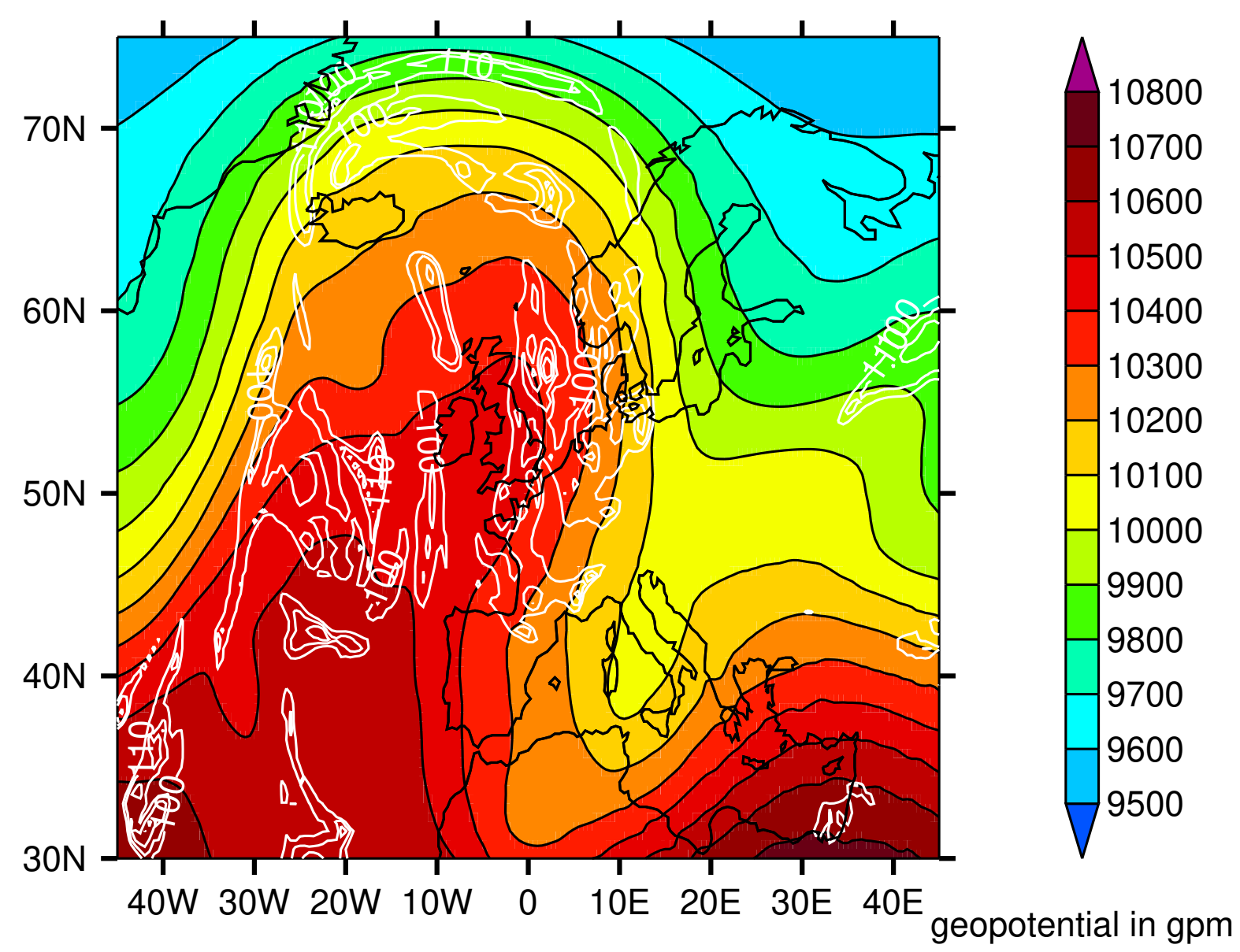

Figure 2. Geopotential height (colour coding) and ice supersaturation (white contours, starting at saturation, increment $10 \%$ ) on the $250 \mathrm{hPa}$ level at 18 UTC on 21 March 2021.

Fig. 2 shows the geopotential height (in gpm) on the $250 \mathrm{hPa}$ level and the locations of ice supersaturation (white contours, in $\%$ ), obtained from ERA5.

At the time of analysis, there is a high-pressure system located over the southern North Atlantic, which is connected to an anticyclonic flow, with a geopotential height of more than $10600 \mathrm{gpm}$. The resulting high-pressure ridge extends further to the north.

The area of Belgium and the Netherlands is influenced by upwards moving air masses, due to the location at the forefront of the high-pressure ridge. There, the geopotential is around $10300 \mathrm{gpm}$ and high values of ice supersaturation are found (white lines). This large ISSR will now be examined in more detail.

In Fig. 3 (as in all further figures to come) we display a longitude-altitude cut through the ISSR along $52^{\circ} \mathrm{N}$. The right panel of the figure shows how this case is simulated in the ERA-5 reanalysis where it is quite a large ISSR, in particular 

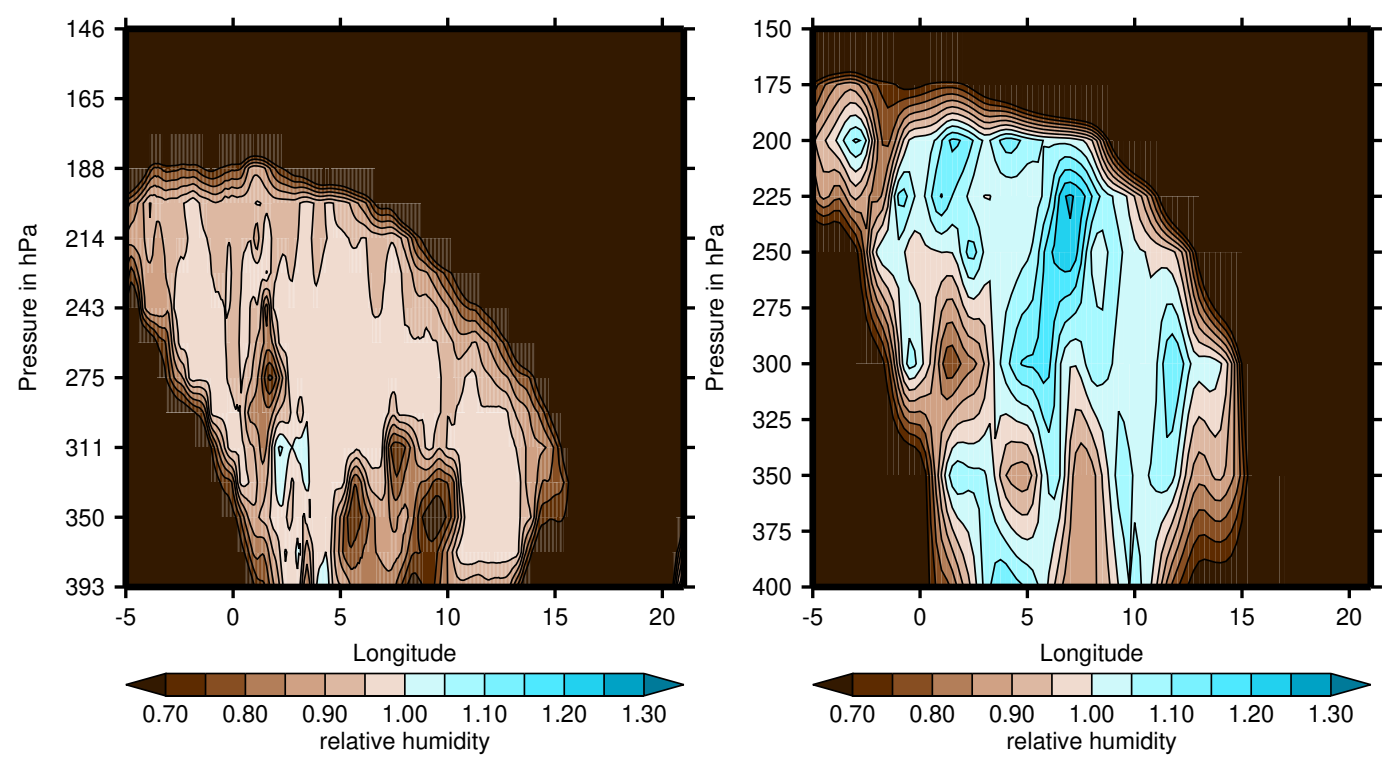

Figure 3. Latitude-altitude plots of relative humidity with respect to ice on 21 March 2021, 18 UTC, along $52^{\circ}$ N. Left panel: data from ICON-EU. Right panel: data from ERA-5. In this figure we display only the upper troposphere and lowermost stratosphere. Please note the different pressure scales in both panels.

vertically. The relative humidity with respect to ice reaches and exceeds $130 \%$ at some locations. Moreover, the figure shows a remarkable small-scale structure with several locations of substantial subsaturation embedded in the supersaturated region. The left panel reveals how this case appeared in the forecast of the ICON-EU model. Obviously, there is a similarly shaped region of high humidity, but saturation or even supersaturation is reached only in small spots. However, the relative humidity is still above 95\% over most of the locations where ERA-5 indicates supersaturation. The embedded dry bubbles appear in both data sets at similar locations, with lower values in the ICON-EU data. The similarity of these patterns is astonishing knowing the difficulties to predict the humidity fields on a small local scale. According to both forecast and reanalysis, the ISSR or almost saturated region was connected to a cirrus cloud, as shown in Fig. 4. As clouds do not form from subsaturated water vapour, this indicates that the ICON-EU model had supersaturation in this region not long before. In the lower part of the cloud, the cloud fraction reaches $100 \%$ in the ICON-EU (less in the reanalysis), but the cloud is quite thin with low cloud fractions in the upper and colder levels. The temperature field is shown for both models in Fig. 5. They appear quite similar to each other. Stippling marks the location of the ISSR. The upper parts of the ISSR and the cloud top have temperatures below $215 \mathrm{~K}$. Such low temperatures imply slow ice growth processes, and as the cloud top is thin with probably low crystal number densities, there are long relaxation times for the supersaturation (e.g. Khvorostyanov and Sassen, 1998). The models do not necessarily reflect this physics, because cloud physics parameterisations in weather- and climate models often assume that the 

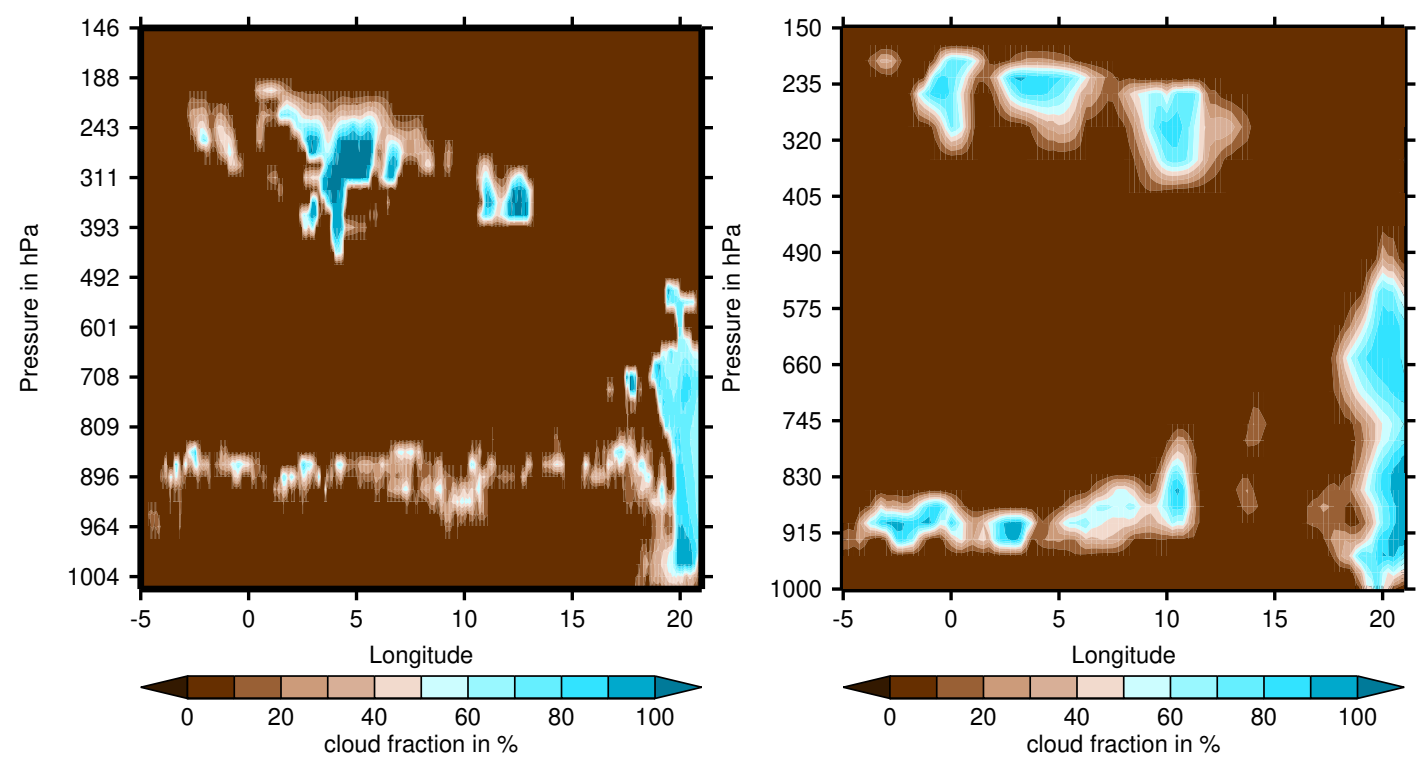

Figure 4. The cloudiness in the same situation, left: ICON-EU, right: ERA-5.

excess supersaturation within a cloud is converted to ice immediately (within the same or next time step); this is known as saturation adjustment.

The statistical results from above lead to the expectation that the lapse rate in the ISSR should be relatively large and this is indeed found in both data sets. Figure 6 shows the lapse rate field computed from the ICON-EU and the ERA5 data. Again the patterns appear quite similar. At the position of the ISSR in the upper troposphere (marked by stippling) there is a maximum in the lapse rates with values exceeding $9 \mathrm{~K} \mathrm{~km}^{-1}$, that is, the stratification is almost neutral. Directly above the ISSR, at the lower boundary of the stratosphere, lapse rates are negative because temperatures increase upwards. Obviously, there is a quite shallow transition zone between almost neutral and very stable stratification (see also Birner et al., 2002; Birner, 2006). In addition, the strong reversal of the lapse rate at about $800 \mathrm{hPa}$ is conspicuous: This is probably an inversion induced by descending movements. Such inversions are typically caused by sinking air masses above a high-pressure system at ground level (subsidence inversion, see e.g., Malberg, 2002). There was indeed a high-pressure system centred southwest of Ireland and elongated in souhtwest-northeastern direction with surface pressures exceeding $1020 \mathrm{hPa}$ over Belgium and the Netherlands. Immler et al. (2008) found with a Lidar based at Lindenberg (southeast of Berlin, Germany) that ice-supersaturation occurred quite frequently in anticyclonic systems and it was almost always found together with thin and sub-visible cirrus clouds. Similarly, a climatological study using ERA-Interim showed that ISSRs occur more often in anticyclonic systems than in cyclones (Gierens and Brinkop, 2012). It is thus no surprise that the ISSR that we look at in this study is in an anticyclonic system as well. 

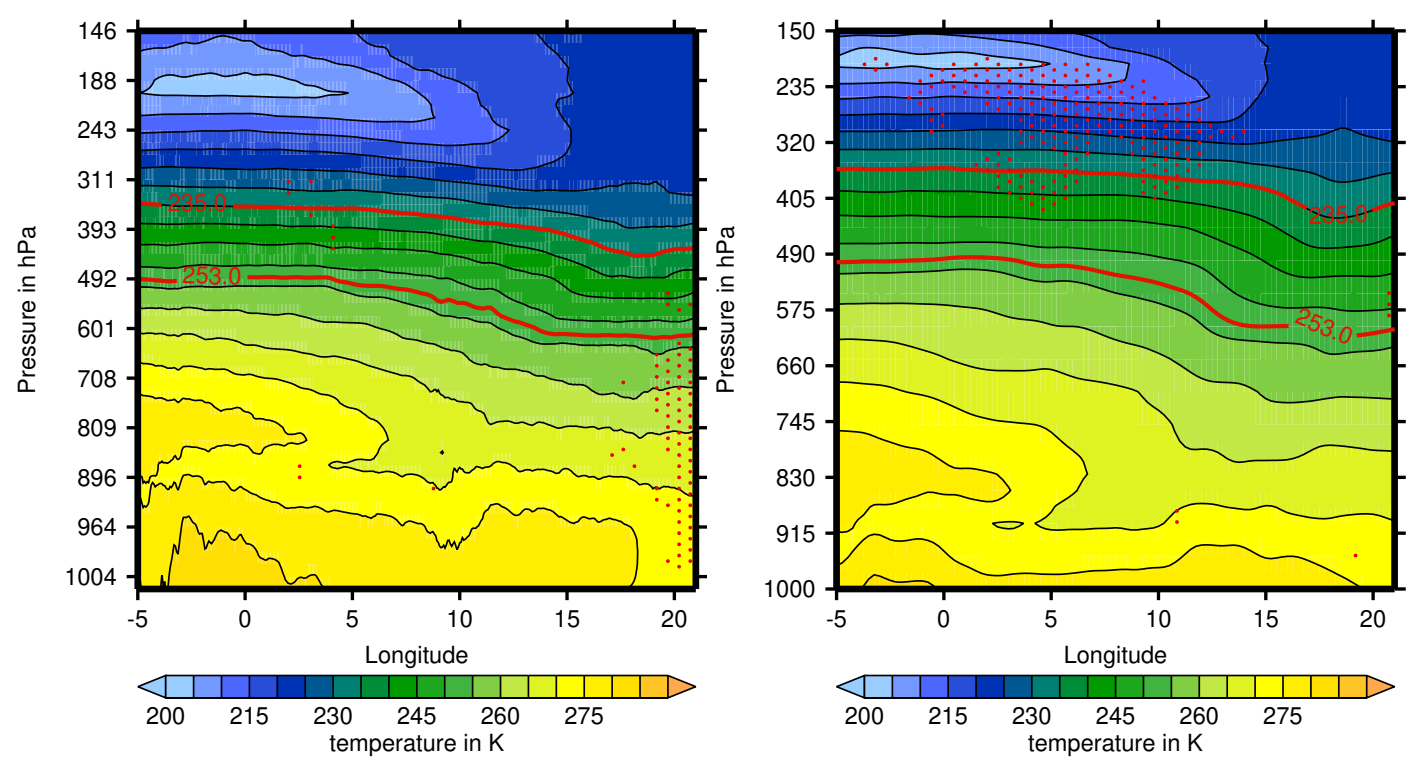

Figure 5. Left panel: Temperature field from ICON-EU. Right panel: Temperature field from ERA-5. The two red lines mark $253 \mathrm{~K}$ and $235 \mathrm{~K}$ for orientation. Below $253 \mathrm{~K}$, the relative humidity in ERA-5 is defined with respect to ice; $235 \mathrm{~K}$ is the threshold for spontaneous freezing of water droplets, that is, below that temperature, condensed water is ice. Ice supersaturation is true at $T<235 \mathrm{~K}$, while above that threshold it might be simply the vapour phase in a supercooled liquid cloud.

Figure 7 shows the field of potential temperature, $\Theta$, again for both models with similar patterns. The vertical gradient of $\Theta$ is quite small within the ISSR (which is equivalent to a near-neutral stratification), but above the ISSR it increases significantly upwards, indicating the transition to the stratosphere, i.e. the tropopause. The tropopause is higher above the ISSR than further to the east, and this longitudinal shape of the zone with the strong $\Theta$-gradient is characteristic for a weather situation with a western high and an eastern low at the ground, and the reverse situation in the upper troposphere.

The isohypses east of the ridge (see Fig. 2) show that the wind reaches $52^{\circ} \mathrm{N}$ approximately from the north, but with a western component. This is seen in Fig. 7 where the wind vectors within the ISSR show a westward direction. In the region with the ISSR there is additionally upward motion due to convergence in the upper troposphere above the surface high pressure. This causes adiabatic cooling (perhaps there is also diabatic cooling due to the cloud), decreasing values of saturation pressures, and thus increasing relative humidity, which favours the formation of supersaturation. The uplifting air also shifts the tropopause upwards. All this results in a nicely coherent pattern with the ISSR directly below the tropopause. This is in general a preferred location for ice-supersaturation (Spichtinger et al., 2003a; Petzold et al., 2020). 

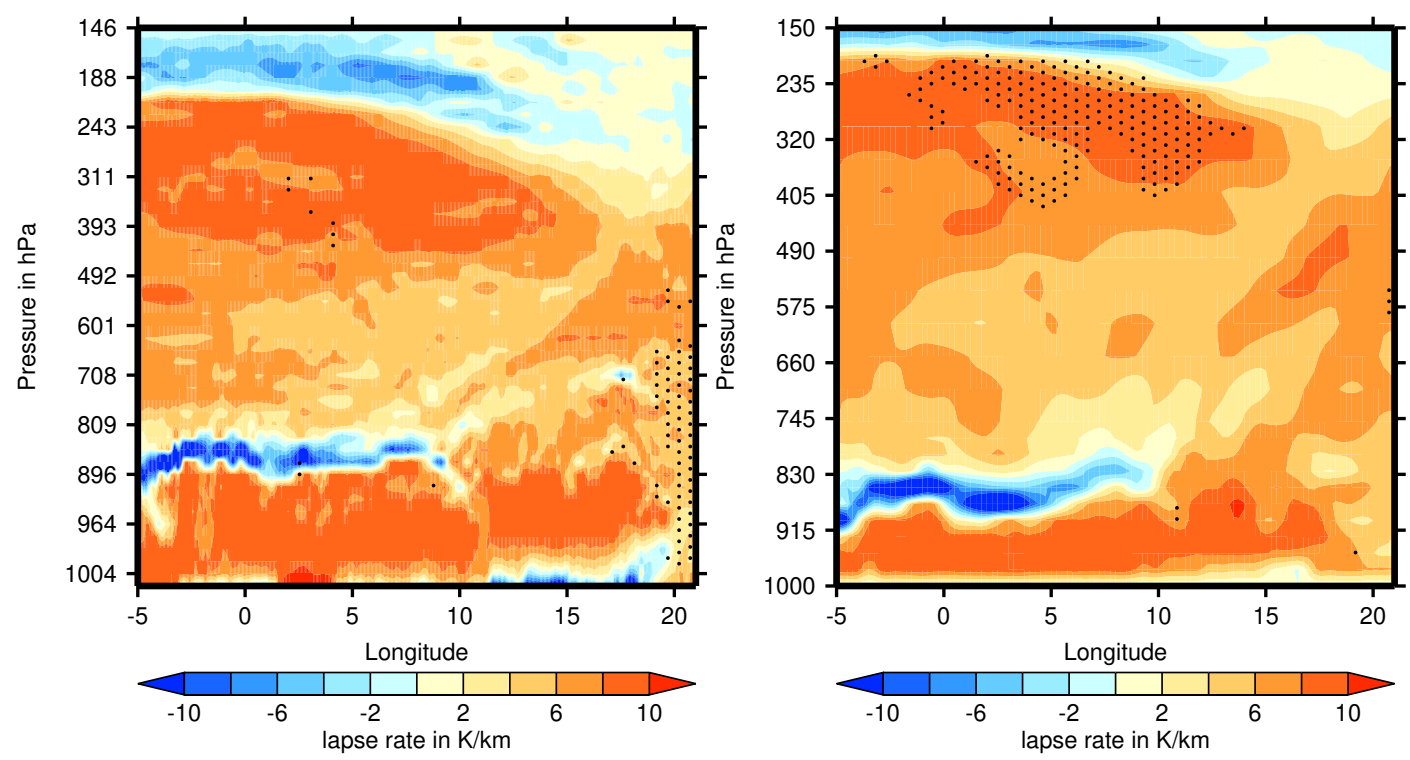

Figure 6. Longitude-altitude plot of atmospheric lapse rates along $52^{\circ} \mathrm{N}$ on March 21,2021 , at 18 UTC. The stippling indicates icesupersaturation. Left panel: ICON-EU, right panel: ERA-5. The vertical axes of the left figure indicate model level number (left) and a mean pressure for each model level (right).

\section{Discussion}

While the statistical facts are clear, that ISSRs in the upper troposphere are regions with large lapse rates or near to neutral stratification, the physics behind this is not yet clear. But without a potential physical mechanism, the statistics could point out merely a correlation instead of a causal relation. In this section, we discuss, therefore, that indeed physical mechanisms exist that can explain high lapse rates within ISSRs. These are the effect of lifting an airmass on its temperature profile, and radiation.

\subsection{Lifting}

Ice supersaturation and cloud formation are generally the result of lifting airmasses. This leads to adiabatic cooling, thus decreasing saturation vapour pressure and increasing relative humidity, until eventually ice supersaturation is reached which may be followed by formation of ice crystals in the upper troposphere. Like subsidence can cause an inversion, lifting causes steepening of temperature gradients. This can be seen as follows: We consider a layer of air, with lower boundary initially at $h_{0}$ and upper boundary at $h_{1}$. The initial lapse rate through this layer is

$225 \gamma=\frac{T_{0}-T_{1}}{h_{1}-h_{0}}$. 

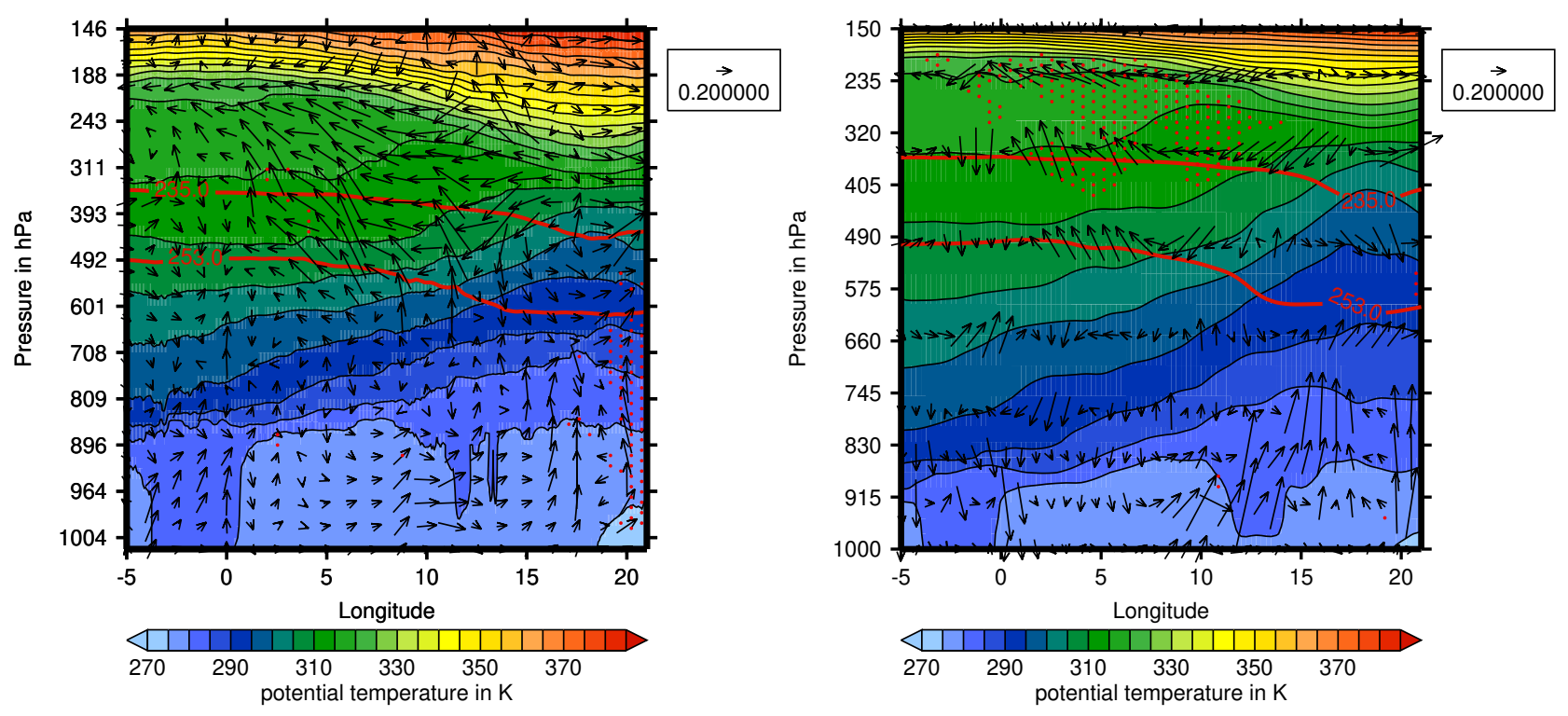

Figure 7. Left panel: Potential temperature field from ICON-eu. Right panel: The same field from ERA-5. The arrows show zonal zonal and vertical wind components, differently normalised in both directions, so that the vertical motions are easily visible.

Now this layer is lifted, such that its lower boundary raises to $h_{0}+\Delta h_{0}$ and similarly for the upper boundary. The temperatures at the boundaries decrease along a dry adiabat (it is not necessary to consider moist adiabats since the water vapour concentration in the upper troposphere is low and the latent heating small). The lapse rate after the lifting is $\gamma^{\prime}$ :

$\gamma^{\prime}=\frac{T_{0}+\Delta T_{0}-\left(T_{1}+\Delta T_{1}\right)}{h_{1}+\Delta h_{1}-\left(h_{0}+\Delta h_{0}\right)}$.

The uplift is adiabatic, such that

$\frac{-\Delta T_{0}}{\Delta h_{0}}=\frac{-\Delta T_{1}}{\Delta h_{1}}=\Gamma$

where $\Gamma=9.76 \mathrm{~K} \mathrm{~km}^{-1}$. The altitude increments depend on each other via the density ratio $k=: \rho_{0} / \rho_{1}$ because of the barometric formula and because the pressure difference through the layer is constant (mass conservation). With $\Delta h_{1}=k \Delta h_{0}$ we get

$235 \gamma^{\prime}=\frac{\gamma\left(h_{1}-h_{0}\right)+\Gamma \Delta h_{0}(k-1)}{\left(h_{1}-h_{0}\right)+\Delta h_{0}(k-1)}$

Dividing both sides by $\gamma$ yields

$\frac{\gamma^{\prime}}{\gamma}=\frac{\left(h_{1}-h_{0}\right)+(\Gamma / \gamma) \Delta h_{0}(k-1)}{\left(h_{1}-h_{0}\right)+\Delta h_{0}(k-1)}$.

Since $\Gamma \geq \gamma$, it follows immediately that $\gamma^{\prime} \geq \gamma$. The limiting cases are $\Delta h_{0}=0$ with $\gamma^{\prime}=\gamma$ (no change) and $\Delta h_{0}(k-1) \gg$ $\left(h_{1}-h_{0}\right)$ with $\gamma^{\prime} \rightarrow \Gamma$. Thus, lifting an airmass leads to a higher lapse rate. 

of the layer:

$\frac{\mathrm{d} \gamma}{\mathrm{d} h_{0}}=\lim _{\Delta h_{0} \rightarrow 0} \frac{\gamma^{\prime}-\gamma}{\Delta h_{0}}=\frac{(\Gamma-\gamma)(k-1)}{\left(h_{1}-h_{0}\right)}$.

Obviously, $(\Gamma-\gamma)(k-1) \rightarrow 0$ when the layer rises, such that $\mathrm{d} \gamma / \mathrm{d} h$ (here we omit the lower index because it is no longer necessary) approaches zero, as well. $\gamma \rightarrow \Gamma$ from below in an asymptotic manner. In the subsidence case, however, these two factors grow, so that $\gamma$ gets smaller with an increasing rate until there is inversion. A simple numerical integration (not shown) confirms these findings.

This derivation assumed dry air, and so it is valid for dry air. It is quite probable that the second maximum of the lapse rate probability density function for subsaturated air (red curve in Fig. 1) is the result of the lifting of rather dry air that does not become supersaturated on lifting. The fact, that the probability maxima at similarly high values of $\gamma$ become much higher as soon as there is ice supersaturation and even higher for Big Hits indicates, that another process must become active that increases $\gamma$ more than lifting does. This process is radiation.

\subsection{Radiation}

The explanation of the radiation effect needs three steps: 1) ISSRs mostly contain ice crystals (although they would not always be classified as a cloud), 2) Even without ice, the moist air has an effect on longwave radiation, with increasing strength with increasing humidity, and if ice crystals form the effect gets still much stronger, 3) The radiative flux divergence leads to warming at the bottom of the ISSR and to cooling at the top, that is, the negative temperature gradient becomes more negative and the lapse rate increases.

When the modern research on ice-supersaturated regions began more than 20 years ago, ISSRs were initially defined as supersaturated but cloud-free air masses. Later it became clear that this definition is too narrow; ice-supersaturation does exist in cloud-free air, but it is much more connected to sub-visible cirrus (Gierens et al., 2000; Immler et al., 2008), and does also exist within (visible) cirrus clouds (Ovarlez et al., 2002; Spichtinger et al., 2004). Sun et al. (2011) find in a study combining satellite data from CERES (Clouds and the Earth's Radiant Energy System), MODIS (Moderate Resolution Imaging Spectroradiometer), and CALIPSO (Cloud-Aerosol Lidar and Infrared Pathfinder Satellite Observation) that about half of the CERES fields of view that MODIS would classify as clear (with a detection threshold for optical thickness of about 0.3) are indeed covered with thin (subvisible) cirrus (as detected by CALIPSO, which has a much lower detection threshold than MODIS). In particular at nighttime there is much subvisible cirrus, four times more than at daytime as the authors find. These thin clouds are mostly close to the tropopause (except in polar regions), and their water vapor mixing ratio is significantly larger than that of air masses where even CALIPSO does not detect any cloud, that is a purely clear sky, which is consistent with early results on ISSRs (Gierens et al., 1999; Spichtinger et al., 2003b). Sun et al. (2011) find also that when subvisible clouds are present in the upper troposphere, they seem to affect the whole temperature and humidity profiles. Only the interaction of the subvisible cloud with radiation can probably cause such far-reaching influence. 
Fusina et al. (2007) investigated the effect of enhanced humidity in ISSRs and of thin cirrus on radiation. They found that ice-supersaturated layers are warmed from below by absorption of longwave radiation from the lower troposphere and ground and cooled at their tops due to emission of radiation to space. It turned out that the warming vs. cooling difference increases with increasing relative humidity. The effect on outgoing longwave radiation (OLR) is small, of the order $<1 \mathrm{~W} \mathrm{~m}^{-2}$, but as soon as there is ice in the ISSR, the effect on OLR increases substantially, consistent with the findings from Sun et al. (2011). Thus, radiation interaction with the enhanced humidity in ISSRs or with the ice crystals in thin (or subvisible) cirrus clouds leads finally to the observed enhancement of lapse rates. Uplifting of the supersaturated layers, as often observed (e.g. in the case described above), close to the tropopause, inhibits the further ascent of the ISSR top, but not of its bottom. This causes the ISSR to get shallower which further increases the lapse rate. Fusina et al. (2007) state also that thicker ISSRs tend to have higher supersaturation maxima, consistent with findings based on radiosonde data (Gierens et al., 2020). High humidity, as stated, causes a strong increase in the lapse rate, and in the presence of aviation it would lead to strong contrails. This may finally explain why the lapse rate distribution is most narrowly confined to the highest values when the thermodynamic conditions (temperature, humidity) allow the formation of strongly warming contrails, Big Hits.

\section{Conclusions}

In the present study we have analysed the influence of ice supersaturation and thin cirrus cloudiness on the lapse rate within such regions. From a combination of ten years of measurement data from the MOZAIC/IAGOS project, from which we take the information on relative humidity at aircraft positions, with ERA-5 reanalysis data, from which we take the information on temperatures on adjacent pressure levels, we determine probability distribution and density functions, conditioned on three situations: 1) subsaturated airmass, 2) ice-supersaturation (or allowing contrail persistence) and 3) situations with strongly warming contrails (Big Hits, a subset of 2). We find that the distributions functions for ISSRs and Big Hits concentrate much to the high end of the lapse rate scale, to slightly stable to neutral stratification cases, in stark contrast to situations without or away from supersaturation. Lapse rates tend to be higher for Big Hits than for the general ISSR, which points to a physical mechanism for steepening the temperature profiles whose efficiency increases with increasing supersaturation.

An example case was then investigated with a large ISSR below the tropopause in the ERA-5 data. For comparison, the same situation was studied as well with forecasts from the ICON-EU model of the German Weather Service. The higher-thanaverage lapse rate was indeed found in both the reanalysis and the forecast for the airmass that is ISS in ERA-5 and almost ISS in ICON-EU. Both data sets show cloudiness in the region of high relative humidity. The patterns of the humidity fields were remarkably similar, but ICON-EU is considerably drier than ERA-5. However, for all other variables we found a high degree of agreement. In both cases we find the enhanced humidity just below a tropopause that was pushed up by uplifting air, which obviously also led to increases of the relative humidity.

Although the common source of supersaturation and cloud formation, uplift and adiabatic cooling of air, causes the lapse rate in the uplifting layer of air to increase, this mechanism alone is insufficient to explain the strong tendency to large lapse rates in supersaturated air. It works for dry air as well, but there is a much stronger effect once the air is moist or even cloudy. 
305 We suggest that radiation is the mechanism that leads to enhanced lapse rates in moist and supersaturated air, and in thin and subvisual cirrus clouds. The mechanism is absorption of infrared radiation from lower warmer layers of the troposphere (or directly from the ground) which heats the lower part of the ISSRs or moist layers. Simultaneously the upper end of this region gives off heat by emitting infrared radiation to space, which implies cooling. Both effects together steepen the temperature profile and thus increase the lapse rate. The mechanism works for cloud free ISSRs, but it gets much stronger as soon as ice is formed, since ice interacts with radiation much stronger than water molecules in the gas phase.

We can thus summarize this paper stating the result that higher than usual lapse rates is another characteristic, and even a quite distinct one, of ice supersaturated regions. This finding adds to the well-known ones, that ISSRs are on average colder and moister than their subsaturated environment.

Author contributions. KG, LW and SH conducted the research and wrote the paper, SR prepared the MOZAIC data and made them available.

Competing interests. The authors declare no competing interests.

Acknowledgements. The research described in this paper contributes to the DLR-internal project Eco2Fly which is coordinated by Volker Grewe. ERA-5 data are provided by the European Copernicus Data Service and ICON-EU data are provided via the Pamore system of the German Weather Service. The first author thanks Axel Kummerow (DWD) for his assistance in making these data available. The kernel density estimation was performed with an IDL program written by David G. Grier, Henrique Moyses, David Ruffner, and Chen Wang. The authors express their special thanks to Andreas Schäfler for his thorough reading and commenting a draft manuscript. A discussion with Michael Ponater on the involved mechanisms is very much appreciated. 


\section{References}

Birner, T.: Fine-scale structure of the extratropical tropopause region, J. Geophys. Res., 111, D04 104, https://doi.org/10.1029/2005JD006301, 2006.

Birner, T., Dörnbrack, A., and Schumann, U.: How sharp is the tropopause at midlatitudes?, Geophys. Res. Lett., 29, 1700, https://doi.org/10.1029/2002GL015142, 2002.

Bland, J., Gray, S., Methven, J., and Forbes, R.: Characterising extratropical near-tropopause analysis humidity biases and their radiative effects on temperature forecasts, Quart. J. Roy. Met. Soc., 147, 3878-3898, https://doi.org/10.1002/qj.4150, 2021.

Copernicus Climate Change Service (C3S): ERA5: Fifth generation of ECMWF atmospheric reanalyses of the global climate, Copernicus Climate Change Service Climate Data Store (CDS), last access April 2020, https://cds.climate.copernicus.eu/cdsapp\#!/home, 2017.

Dee, D., Uppala, S., Simmons, A., Berrisford, P., Poli, P., Kobayashi, S., Andrae, U., Balmaseda, M., Balsamo, G., Bauer, P., Bechtold, P., Beljaars, A., van de Berg, L., Bidlot, J., Bormann, N., Delsol, C., Dragani, R., Fuentes, M., Geer, A., Haimberger, L., Healy, S., Hersbach, H., Hólm, E., Isaksen, L., Kållberg, P., Köhler, M., Matricardi, M., McNally, A., Monge-Sanz, B., Morcrette, J.-J., Park, B.-K., Peubey, C., de Rosnay, P., Tavolato, C., Thépaut, J.-N., and Vitart, F.: The ERA-Interim reanalysis: configuration and performance of the data assimilation system, Quart. J. Roy. Met. Soc., 137, 553-597, https://doi.org/10.1002/qj.828, 2011.

Fusina, F., Spichtinger, P., and Lohmann, U.: Impact of ice supersaturated regions and thin cirrus on radiation in the midlatitudes, J. Geophys. Res., 112, D24S14, doi:10.1029/2007JD008 449, 2007.

Gierens, K. and Brinkop, S.: Dynamical characteristics of ice supersaturated regions, Atmos. Chem. Phys., 12, 11933 -11 942, 2012.

Gierens, K. and Spichtinger, P.: On the size distribution of ice-supersaturated regions in the upper troposphere and lowermost stratosphere, Ann. Geophys., 18, 499-504, 2000.

Gierens, K., Schumann, U., Helten, M., Smit, H., and Marenco, A.: A distribution law for relative humidity in the upper troposphere and lower stratosphere derived from three years of MOZAIC measurements, Ann. Geophys., 17, 1218-1226, 1999.

Gierens, K., Schumann, U., Helten, M., Smit, H., and Wang, P.: Ice-supersaturated regions and sub visible cirrus in the northern midlatitude upper troposphere, J. Geophys. Res., 105, 22 743-22 754, 2000.

Gierens, K., Spichtinger, P., and Schumann, U.: Ice supersaturation, in: Atmospheric Physics. Background — Methods — Trends, edited by Schumann, U., chap. 9, pp. 135-150, Springer, Heidelberg, Germany, 2012.

Gierens, K., Wilhelm, L., Sommer, M., and Weaver, D.: On ice supersaturation over the Arctic, Meteorol. Z., 29, 10 pp., https://doi.org/10.1127/metz/2020/1012, 2020.

Hersbach, H., Bell, B., Berrisford, P., Biavati, G., Horányi, A., Muñoz Sabater, J., Nicolas, J., Peubey, C., Radu, R., Rozum, I., Schepers, D., Simmons, A., Soci, C., Dee, D., and Thépaut, J.-N.: ERA5 hourly data on single levels from 1979 to present, Tech. rep., Copernicus Climate Change Service (C3S) Climate Data Store (CDS), https://doi.org/10.24381/cds.adbb2d47, accessed on 14-Jul-2021, 2018a.

Hersbach, H., Bell, B., Berrisford, P., Biavati, G., Horányi, A., Muñoz Sabater, J., Nicolas, J., Peubey, C., Radu, R., Rozum, I., Schepers, D., Simmons, A., Soci, C., Dee, D., and Thépaut, J.-N.: ERA5 hourly data on pressure levels from 1979 to present, Tech. rep., Copernicus Climate Change Service (C3S) Climate Data Store (CDS), https://doi.org/10.24381/cds.bd0915c6, accessed on 14-Jul-2021, 2018b.

Hersbach, H., Bell, B., Berrisford, P., Hirahara, S., Horányi, A., Muñoz Sabater, J., Nicolas, J., Peubey, C., Radu, R., Schepers, D., Simmons, A., Soci, C., Abdalla, S., Abellan, X., Balsamo, G., Bechtold, P., Biavati, G., Bidlot, J., Bonavita, M., De Chiara, G., Dahlgren, P., Dee, D., Diamantakis, M., Dragani, R., Flemming, J., Forbes, R., Fuentes, M., Geer, A., Haimberger, L., Healy, S., Hogan, R. J., Hólm, E., 
Janisková, M., Keeley, S., Laloyaux, P., Lopez, P., Lupu, C., Radnoti, G., de Rosnay, P., Rozum, I., Vamborg, F., Villaume, S., and Thépaut, J.-N.: The ERA5 global reanalysis, Quart. J. Roy. Met. Soc., 146, 1999-2049, https://doi.org/10.1002/qj.3803, 2020. systems at northern mid latitudes, Atmos. Chem. Phys., 8, 1689-1699, 2008.

Khvorostyanov, V. and Sassen, K.: Cirrus cloud simulation using explicit microphysics and radiation. Part II: Microphysics, vapor and ice mass budgets, and optical and radiative properties, J. Atmos. Sci., 55, 1822-1845, 1998.

Malberg, H.: Meteorologie und Klimatologie: Eine Einführung, Springer, Berlin, 4th edn., 2002.

Marenco, A., Thouret, V., Nedelec, P., Smit, H., Helten, M., Kley, D., Karcher, F., Simon, P., Law, K., Pyle, J., Poschmann, G., Wrede, R. V., Hume, C., and Cook, T.: Measurement of ozone and water vapor by Airbus in-service aircraft: The MOZAIC airborne program, An overview, J. Geophys. Res., 103, 25 631-25 642, 1998.

Neis, P., Smit, H., Rohs, S., Bundke, U., Krämer, M., Spelten, N., Ebert, V., Buchholz, B., Thomas, K., and Petzold, A.: Quality assessment of MOZAIC and IAGOS capacitive hygrometers: insights from airborne field studies, Tellus B: Chemical and Physical Meteorology, 67, 1, https://doi.org/10.3402/tellusb.v67.28320, 2015.

Ovarlez, J., Gayet, J.-F., Gierens, K., Ström, J., Ovarlez, H., Auriol, F., Busen, R., and Schumann, U.: Water vapour measurements inside cirrus clouds in northern and southern hemispheres during INCA, Geophys. Res. Lett., 29, 1813, doi:10.1029/2001GL014 440, 2002.

Petzold, A., Thouret, V., Gerbig, C., Zahn, A., Brenninkmeijer, C., Gallagher, M., Hermann, M., Pontaud, M., Ziereis, H., Boulanger, D., Marshall, J., Nedelec, P., Smit, H., Friess, U., Flaud, J.-M., Wahner, A., Cammas, J.-P., and Volz-Thomas, A.: Global-scale atmosphere monitoring by in-service aircraft - current achievements and future prospects of the European Research Infrastructure IAGOS, Tellus B, 67, https://doi.org/10.3402/tellusb.v67.28452, http://www.tellusb.net/index.php/tellusb/article/view/28452, 2015.

Petzold, A., Neis, P., Rütimann, M., Rohs, S., Berkes, F., Smit, H., Krämer, M., Spelten, N., Spichtinger, P., Nedelec, P., and Wahner, A.: Ice-supersaturated air masses in the northern mid-latitudes from regular in situ observations by passenger aircraft: vertical distribution, seasonality and tropospheric fingerprint, Atmos. Chem. Phys., 20, 8157-8179, https://doi.org/10.5194/acp-20-8157-2020, 2020.

Silverman, B. W.: Density Estimation for Statistics and Data Analysis, no. 26 in Monographs on Statistics and Applied Probability, Chapman and Hall/CRC, Boca Raton, 1998.

Spichtinger, P., Gierens, K., Leiterer, U., and Dier, H.: Ice supersaturation in the tropopause region over Lindenberg, Germany, Meteorol. Z., 12, 143-156, 2003a.

Spichtinger, P., Gierens, K., and Read, W.: The global distribution of ice-supersaturated regions as seen by the Microwave Limb Sounder, Quart. J. Roy. Met. Soc., 129, 3391-3410, 2003b.

Spichtinger, P., Gierens, K., Smit, H., Ovarlez, J., and Gayet, J.-F.: On the distribution of relative humidity in cirrus clouds, Atmos. Chem. Phys., 4, 639-647, 2004.

Sun, W., Videen, G., Kato, S., Lin, B., Lukashin, C., and Hu, Y.: A study of subvisual clouds and their radiation effect with a synergy of CERES, MODIS, CALIPSO, and AIRS data, J. Geophys. Res., 116, 1-10, https://doi.org/10.1029/2011JD016422, 2011.

Tompkins, A., Gierens, K., and Rädel, G.: Ice supersaturation in the ECMWF Integrated Forecast System, Quart. J. Roy. Met. Soc., 133, 53-63, 2007.

Wegener, A.: Meteorologische Terminbeobachtungen am Danmarks-Havn, in: Meddelelser om Grønland, Vol. XLII: Danmark-Ekspeditionen til Grønlands Nordøstkyst 1906-1908, Vol. II, pp. 125-356, Kommissionen for ledelsen af de geologiske og geografiske unders $\emptyset$ gelser i Grønland, 1914. 
https://doi.org/10.5194/acp-2022-117

Preprint. Discussion started: 24 February 2022

(C) Author(s) 2022. CC BY 4.0 License.

(c) (1)

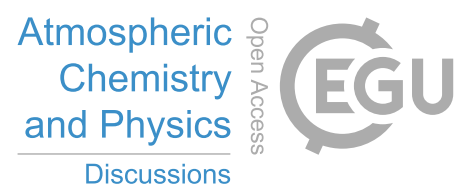

395 Wilhelm, L., Gierens, K., and Rohs, S.: Weather variability induced uncertainty of contrail radiative forcing, Aerospace, 8, https://doi.org/10.3390/aerospace8110332, 2021.

Zängl, G., Reinert, D., Ripodas, P., and Baldauf, M.: The ICON (ICOsahedral Non-hydrostatic) modelling framework of DWD and MPI-M: Description of the non-hydrostatic dynamical core, QJRMS, 141, 563-579, https://doi.org/10.1002/qj.2378, 2015. 